\title{
Pancreatic enzymes in the epithelium of intrahepatic large bile ducts and in hepatic bile in patients with extrahepatic bile duct obstruction
}

T Terada, T Morita, M Hoso, Y Nakanuma

\begin{abstract}
Aim-To determine whether pancreatic enzymes are present in hepatic bile and in intrahepatic bile duct epithelium.

Methods-The activity and proteins of pancreatic enzymes (pancreatic a-amylase, lipase, trypsin/trypsinogen) in hepatic bile were investigated using biochemical and western blot analyses in 25 patients with extrahepatic bile duct obstruction. Immunolocalisation of enzyme proteins was evaluated by immunohistochemistry in 20 necropsy livers with extrahepatic bile duct obstruction.

Results-Western blot analysis showed proteins of pancreatic a-amylase, lipase, and trypsin in 19 of $25(76 \%), 10$ of 25 $(40 \%)$, and 14 of 25 (56\%) patients, respectively. Pancreatic $\alpha$-amylase and lipase activities was present in every bile specimen. Radioimmunoassay showed that trypsin was present in every bile sample. Immunohistochemically, the immunoreactivity of the three enzymes was present in epithelia and in the lumina of intrahepatic large bile ducts, septal bile ducts, and peribiliary glands in all cases.

Conclusions-These results strongly suggest that biliary epithelia of larger intrahepatic ducts produce pancreatic $a$-amylase, lipase, and trypsin, and that these enzymes are secreted into the lumina of intrahepatic bile ducts.
\end{abstract}

(F Clin Pathol 1994;47:924-927)

It has become increasingly evident that intrahepatic bile ducts not only drain canalicular bile but also have a variety of functions including secretion and absorption of water and electrolytes, ${ }^{1}$ secretion of mucous, ${ }^{2}$ secretion of $\operatorname{IgA},{ }^{3}$ secretion of lactoferrin and lysozyme, ${ }^{4}$ and presence of neuroendocrine hormones. ${ }^{5}$ The degree of these functions varies with the anatomical segments and the type of bile duct. Recently, it has become evident that intrahepatic large bile ducts, septal bile duct, and peribiliary glands express immunoreactive pancreatic $a$-amylase, pancreatic lipase, and trypsin in normal human liver and in various hepatobiliary diseases. ${ }^{6-8}$ However, it is unknown whether these pancreatic enzymes occur in hepatic bile.

\section{Methods}

Hepatic bile was collected from 25 patients with extrahepatic biliary obstruction (choledocholithiasis $n=10$; extrahepatic bile duct carcinoma $n=6$; pancreatic carcinoma $n=5$; cholangiocarcinoma of hilar type $n=4$ ). These patients had undergone percutaneous transhepatic catheter drainage to reduce obstructive jaundice. The 25 bile samples (each $10 \mathrm{ml}$ ) obtained from the catheter were immediately frozen and stored at $-80^{\circ} \mathrm{C}$ until use.

Pancreatic $a$-amylase activity was measured using the Amylase Kit EPS (BoehringerMannheim Co. Ltd., Germany) which requires ethilidine-(G7)-1-4-nitrophenyl-(G1)$\alpha$-D-maltohepaoside as the substrate. ${ }^{9}$ Pancreatic lipase activity was measured (Lipase Kit-VE, Nihon Shoji Ltd., Tokyo, Japan) according to the method of Imamura and Misaki. ${ }^{10}$ Because trypsin inhibitor may be present in hepatic bile, trypsin was measured $(\mathrm{ng} / \mathrm{ml})$ using a radioimmunoassay kit (Ria-Gnost Trypsin II; Behring-Werke Co. Ltd., Marburg, Germany).

The protein concentration of bile samples was measured according to the method of Lowry et al. ${ }^{11}$ The bile samples containing 100 $\mu \mathrm{g}$ protein were solubilised at $100^{\circ} \mathrm{C}$ for five minutes in $50 \mu \mathrm{l}$ sample buffer $(50 \mathrm{mM}$ TRIS-HCl (pH 6.8), $2 \%$ sodium dodecyl sulphate (SDS), $10 \%$ 2-mercaptoethanol, $0 \cdot 1 \%$ bromophenol blue, and $10 \%$ glycerol). Bile proteins were separated on $10 \%$ SDS polyacrylamide electrophoresis gels at $60 \mathrm{~mA}$ for two hours at room temperature. The gels were then equilibrated for 30 minutes in transfer buffer (50 mM TRIS, $40 \mathrm{mM}$ glycine, 0.04\% SDS, and $30 \%$ methanol). Proteins were electrophoretically transferred on to nylon membranes (Immobiron PVDF Transfer Membrane; Daiichi Pure Chemicals, Ltd., Tokyo, Japan) at $120 \mathrm{~mA}$ for 60 minutes. The membranes were incubated in blocking buffer (phosphate buffered saline (PBS) containing $3 \%$ bovine serum albumin) for 12 hours at $4^{\circ} \mathrm{C}$. For detection of pancreatic $a$-amylase, lipase, and trypsin, the membranes were incubated for 60 minutes at room temperature in mouse monoclonal antibody (IgG class) against human pancreatic $a$-amylase (Chemicon Inc., Tomecula, California, USA; dilution 1 in 100), mouse monoclonal antibody (IgG class) against human pancreatic lipase (Chemicon Inc.; dilution 1 in 
100), or mouse monoclonal antibody (IgG class) against human trypsinogen-trypsin (Chemicon Inc.; dilution 1 in 100). After two washes in T-PBS $(0.03 \%$ Tween 20 and PBS (pH7.2), the membranes were incubated for 60 minutes at room temperature with peroxidase labelled goat anti-mouse IgG (Dako Corporation, Santa Barbara, California, USA; dilution 1 in 1500) in T-PBS. After three washes in T-PBS the membranes were incubated at room temperature with development buffer ( $50 \mathrm{mM}$ TRIS-HCl (pH7.2), 0.025\% diaminobenzidine, and $0.075 \%$ hydrogen peroxide). As positive controls the same procedures were performed using human pancreatic $a$-amylase (Athens Research and Technology Inc., Athens, Georgia, USA), human pancreatic lipase (Elastin Products Co. Ltd., Owensville, Michigan, USA), and human trypsin (Athens Research and Technology Inc.).

A total of 20 recent necropsy livers with extrahepatic biliary obstruction were obtained from patients aged $47-86$ years $(12$ men and eight women). Five tissue specimens containing large bile ducts were obtained from each liver, fixed in $4 \%$ formaldehyde, and embedded in paraffin wax. As positive controls specimens of the normal pancreas were obtained from our surgical files, fixed in $4 \%$ formaldehyde, and embedded in paraffin wax. Several serial $5 \mu \mathrm{m}$ sections were obtained from each paraffin wax block, and one of them was stained with haematoxylin and eosin.

Three serial sections from every block were immunostained for pancreatic $a$-amylase, pancreatic lipase, and trypsin by the threestep indirect immunoperoxidase method (avidin biotin peroxidase method) of $\mathrm{Hsu} e t$ al. ${ }^{12}$ The primary antibodies used were the same as those used in the western blot assay. The sections were treated with the optimally diluted primary antibodies at $4^{\circ} \mathrm{C}$ overnight. The sections were next incubated with the secondary biotinylated antibody (anti-mouse IgG; Vector Laboratories, Burlingame, California, USA) for 40 minutes and subsequently treated with avidin biotin peroxidase complex (Vectastain ABC Kit, Vector Laboratories) for 40 minutes. Reaction products were developed by immersing the sections in a 3,3'-diaminobenzidine tetrahydrochloride solution (Sigma Chemicals, St Louis, Missouri, USA) containing hydrogen peroxide. Positive staining was abolished when non-immune sera or PBS were substituted for the primary antibodies. In five cases the immunostaining was performed with Vector Red (Vector Laboratories) instead of diaminobenzidine. Vector red produces red fluorescence under a fluorescence microscope with a hodamine filter system. The specimens were examined under a confocal laser scanning microscope (LSMGB200, Olympus, Tokyo, Japan). An argon laser with a $514.4 \mathrm{~nm}$ wavelength and a 615 $\mathrm{nm}$ long-pass barrier filter made confocal fluorescence images.

Absorption tests were also performed in selected specimens during each immuno-

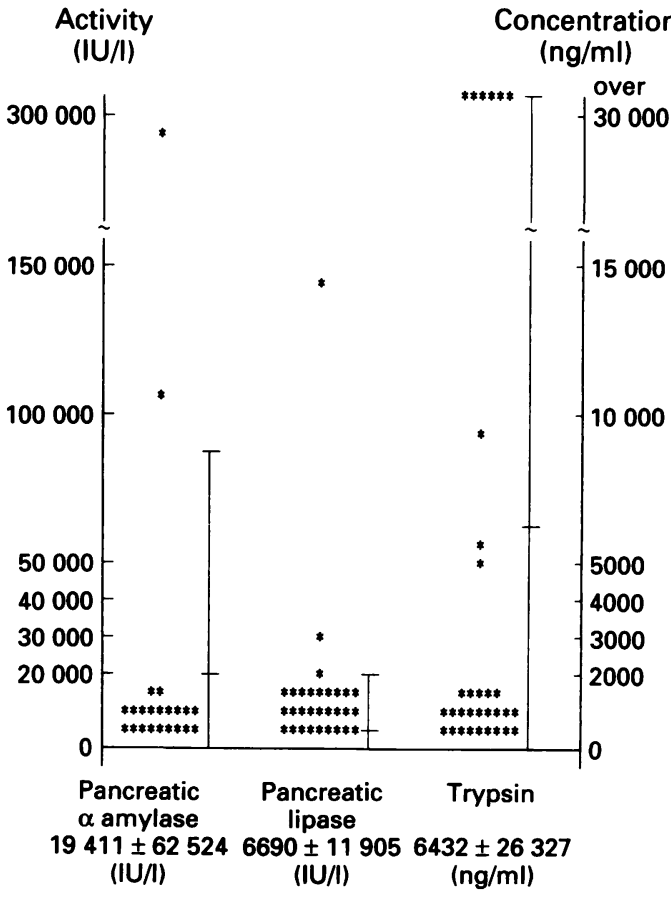

Figure 1 Pancreatic a-amylase and lipase activities and trypsin concentrations in the hepatic bile of patients with extrahepatic bile duct obstruction. Each dot represents a single bile sample.

staining procedure. The absorbents included human pancreatic $a$-amylase (Athens Research and Technology Inc.), human pancreatic lipase (Elastin Products Co. Ltd.), and human trypsin (Athens Research and Technology Inc.).

\section{Results}

Figure 1 shows the pancreatic a-amylase, pancreatic lipase, and trypsin activities. Pancreatic $a$-amylase and lipase were present in all 25 bile samples (pancreatic $a$-amylase, mean $19411 \mathrm{IU} / 1$; pancreatic lipase mean = $6690 \mathrm{IU} / 1)$, although the values varied greatly according to the bile samples. Trypsin was present in all 25 bile samples (mean 6432 $\mathrm{ng} / \mathrm{ml}$ ), although this varied greatly with the bile samples.

Western blotting of pancreatic $a$-amylase revealed a signal at 54 kilodaltons in 19 of 25 (76\%) of the bile samples (fig 2). Signals for trypsin and pancreatic lipase were noted at 23 and 52 kilodaltons in 10 of $25(40 \%)$ and 14 of $25(56 \%)$, respectively (fig 2 ). The locations of the signals were consistent with the molecular weight of the enzymes and corresponded to the signals of positive controls (fig 2). The activities of these enzymes were much higher in bile samples with signals (pancreatic $a$ amylase, mean $22872 \mathrm{IU} / 1$; trypsin mean $9831 \mathrm{ng} / \mathrm{ml}$; pancreatic lipase mean 18060 IU/1) than in those without signals (pancreatic $a$-amylase, mean $126 \mathrm{IU} / 1$; trypsin, mean 351 $\mathrm{ng} / \mathrm{ml}$; pancreatic lipase, mean $101 \mathrm{IU} / \mathrm{l}$ ).

The acinar cells of the normal pancreas were positive for pancreatic $a$-amylase, lipase, and trypsin, and were negative by the absorption test, suggesting that each immunostain is specific. Immunoreactivity to pancreatic 
Figure 2 Western blot analysis of hepatic bile. $A$ signal (arrow) is seen at 54 kilodaltons in pancreatic a-amylase immunoblots. $A$ signal (arrow) is seen at 23 kilodaltons in trypsin immunoblots. $A$ signal (arrow) is seen at 52 kilodaltons in pancreatic lipase immunoblots. The locations of the signals of samples $(S)$ are consistent of the respective enzymes, and correspond to the signals of positive controls (C). $M=$ molecular weight marker. with the molecular weight
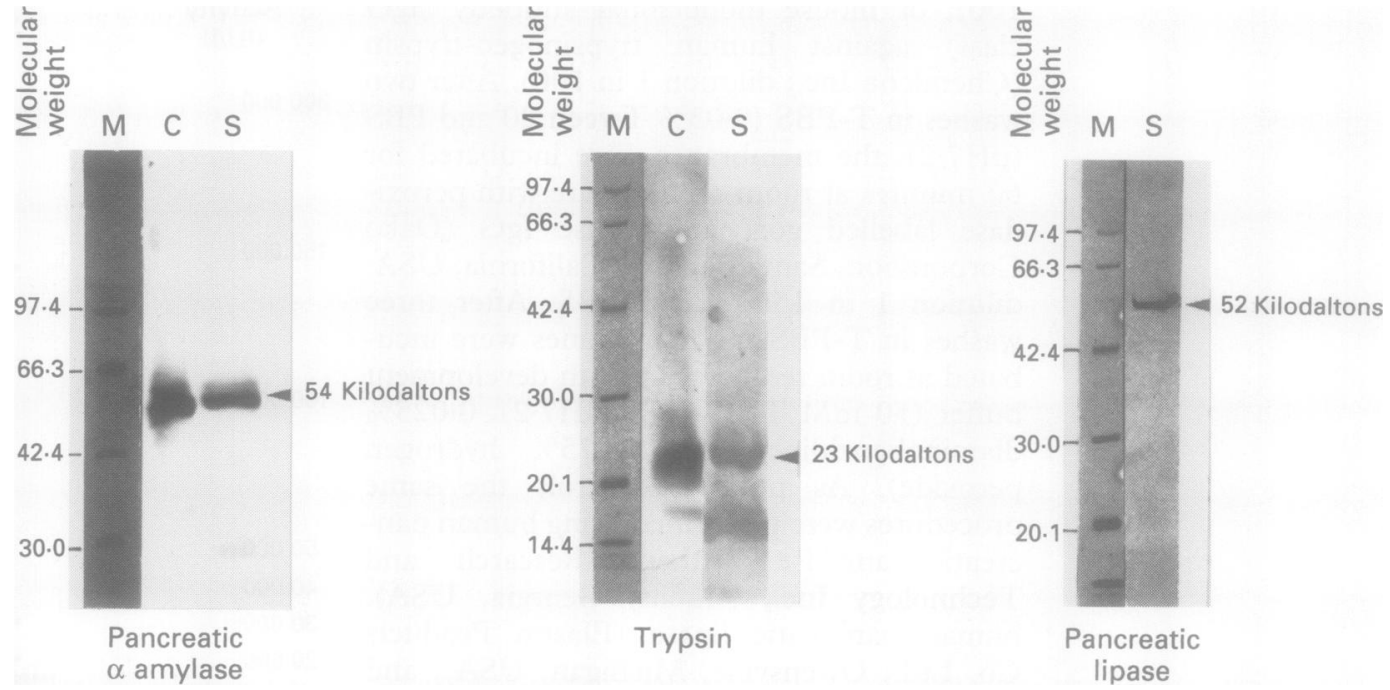

Figure 3 Confocal laser scanning images of intrahepatic large bile ducts immunostained for

pancreatic a-amylase $(A)$, lipase (B), and trypsin (C). The biliary epithelial cells are positive for the three enzymes. The lumina are also positive for the enzymes, and the enzymes seem to be secreted from the biliary epithelia (immunostain).
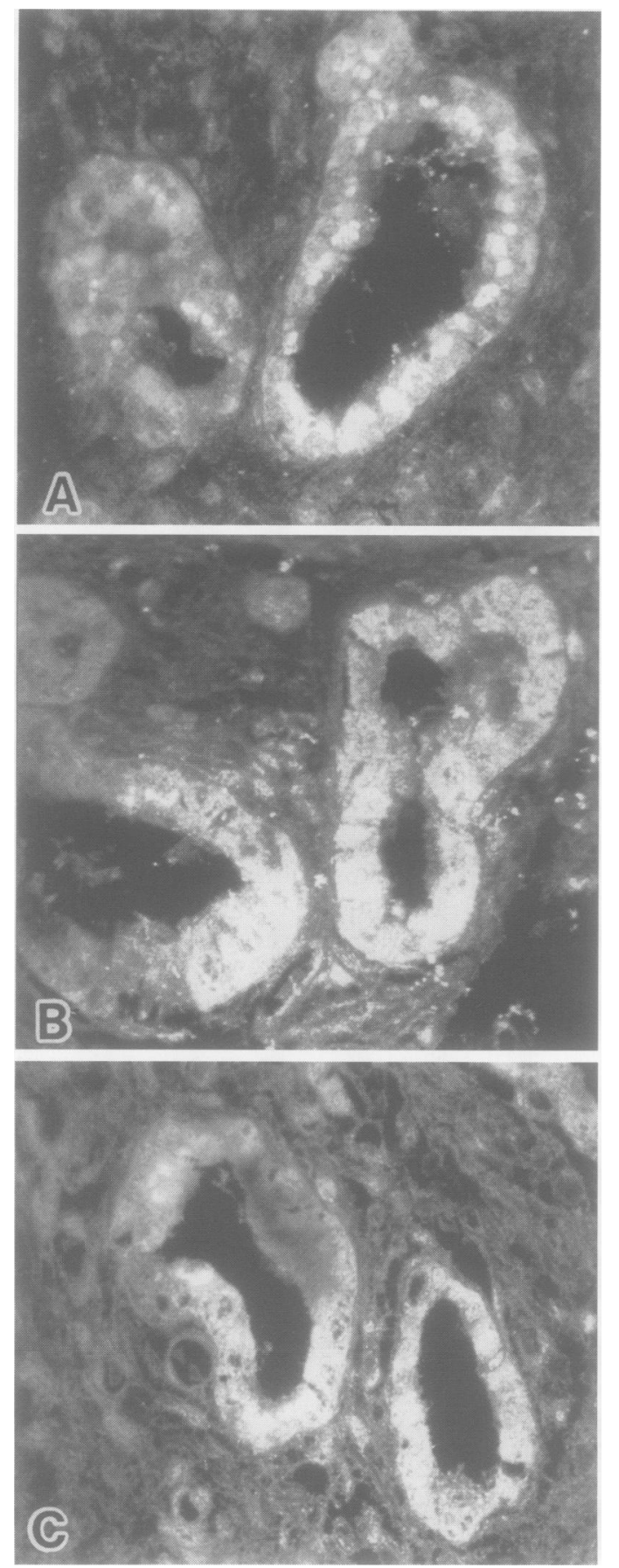

$a$-amylase, pancreatic lipase, and trypsintrypsinogen was present in the epithelial cells of the intrahepatic large bile ducts, septal bile ducts, and peribiliary glands in all cases (figs 3A-C). The lumina of the bile ducts and peribiliary glands were also positive for the three enzymes, and the luminal enzymes seemed to be secreted from the biliary epithelia (figs 3AC). The immunoreactivities became negative with the absorption test. These enzymes were absent in interlobular bile ducts, bile ductules, and hepatocytes.

\section{Discussion}

In this study, the activities of the three enzymes were present in all bile samples from patients with extrahepatic bile duct obstruction, indicating that pancreatic $a$-amylase, pancreatic lipase, and trypsin are present in hepatic bile. The reason why the enzyme activities varied greatly according to the bile samples remains to be clarified.

Western blot analysis confirmed the presence of pancreatic $a$-amylase, pancreatic lipase, and trypsin proteins in the hepatic bile. However, there was a discrepancy between enzyme activity and results of western blot analysis: enzyme activities were present in all bile samples while proteins were detected in only $40-76 \%$ of samples by western blot analysis. The reason for this discrepancy may have been that the western blot technique is less sensitive than the biochemical techniques measuring enzyme activity because enzyme activities in bile samples evaluated with western blot signals were high whereas those in bile samples with no western blot signals were low.

This study has shown that immunoreactive pancreatic $a$-amylase, lipase, and trypsintrypsinogen occur in the epithelium of intrahepatic large bile ducts, septal bile ducts, and peribiliary glands in necropsy livers from patients with extrahepatic bile duct obstruction. The immunoreactivity became negative in the absorption test, suggesting that each immunostain is specific. This finding strongly suggests that epithelial cells in intra- 
hepatic large bile ducts, septal bile ducts, and peribiliary glands contain pancreatic $a$-amylase, pancreatic lipase, and trypsinogentrypsin. Of particular interest was that enzyme immunoreactivity seemed to be secreted from the biliary epithelium into bile duct lumina. Because these enzymes were detected in hepatic bile, these biliary epithelial cells are very likely to be the cellular source of the enzymes.

Finally, our experiment was confined to hepatic bile in patients with extrahepatic bile duct obstruction. We did not examine normal human hepatic bile, because it is very difficult or impossible to obtain normal human hepatic bile. It remains to be elucidated whether normal human hepatic bile contains pancreatic enzymes.

In conclusion, our data strongly suggest that the biliary epithelia of larger intrahepatic ducts produce pancreatic $a$-amylase, lipase, and trypsin, and that these enzymes are secreted into the lumina of intrahepatic bile ducts.

1 Sasaki H, Schaffner F, Popper H. Bile ductules in cholestasis: morphologic evidence for secretion and absorption in man. Lab Invest 1967;16:84-95.

2 Terada T, Nakanuma Y. Development of human intrahepatic peribiliary glands: histological, keratin immunohistochemical and mucus histochemical analyses. Lab Invest 1993;68:261-9.

3 Sugiura $H$, Nakanuma $Y$. Secretory components and immunoglobulins in the intrahepatic biliary tree and peribiliary glands in the intrahepatic biliary tree and peribiliary glands in normal livers

4 Saito K, Nakanuma Y. Lactoferrin and lysozyme in the intrahepatic bile duct of normal livers and hepatolithiasis. F Hepatol 1992;15:147-53.

5 Roskam T, Van der Oord J, De Vos R, Desmet VJ. Neuroendocrine features of reactive bile ductules in cholestatic liver disease. Am F Pathol 1990;137:1019-25.

6 Terada T, Nakanuma Y. Expression of alpha-amylase isoenzymes and trypsin by the proliferating epithelium of large intrahepatic bile ducts and intrahepatic peribiliary glands in hepatolithiasis. Histopathology 1993;22:467-73.

7 Terada T, Nakanuma Y. Pancreatic lipase is a useful phenotypic marker of intrahepatic large and septal bile ducts, peribiliary glands, and their malignant counterparts. Mod Pathol 1993;6:419-26.

8 Terada T, Kida T, Nakanuma Y. Extrahepatic peribiliary glands express alpha-amylase isozymes, trypsin and pancreatic lipase: an immunohistochemical analysis. Hepatology 1993;18:803-8.

9 Rauscher E, Bulow S, Hagele EO, Neumann U, Schaich E. Ethylidine protected substrate for the assay of human al .

10 Imanura S, Misaki H. A sensitive method for assay of lipase activity by coupling with beta-oxidation enzymes lipase activity by coupling with beta-oxidation en

11 Lowry OH, Rosebrough NJ, Farr AL, Randall RJ. Protein mewry OH, Rosebrough NJ, Farr AL, Randall RJ. Protein
measurement with the folin phenol reagent. $\mathcal{f}$ Biol Chem 1951;193:265-75.

12 Hsu SM, Raine L, Fanger H. Use of avidin-biotin-peroxidase complex (ABC) in immunoperoxidase techniques: a comparison between ABC and unlabelled (PAP) procedures. F Histochem Cytochem 1981;29:557-80. 